\title{
IMPLICATION OF PROCESS PARAMETERS OF SINGLE POINT INCREMENTAL FORMING FOR CONICAL FRUSTUM CUPS FROM
}

\section{AA 1070 USING FEA}

\author{
A. Ravi Teja ${ }^{1}$, A. Chennakesava Reddy ${ }^{2}$ \\ ${ }^{I} P G$ Student Department of Mechanical Engineering, JNTUH College of Engineering, Hyderabad, Telangana, India \\ ${ }^{2}$ Professor, Department of Mechanical Engineering, JNTUH College of Engineering, Hyderabad, Telangana, India
}

\begin{abstract}
Simulation of single point incremental deep drawing process for AA1070 sheet with the help of finite element software and Taguchi experimental techniques. Blank thickness, step depth, tool radius and coefficient of friction are the process parameters for the conical frustum cups. It has been found that the tool radius and coefficient of friction are highly influential in controlling the formability of cups.
\end{abstract}

Keywords: Single Point Incremental Deep Drawing Process, AA1070, Conical Cups, Blank Thickness, Tool Radius, Step Depth, Coefficient of Friction, Conical Frustum Cups.

\section{INTRODUCTION}

Some classic sheet metal forming processes are stamping, drawing, and pressing. In these processes, commonly used in the industry, a blank of sheet metal is clamped around the edges, while the middle section is forced by a punch into a die to stretch the metal into the desired shape. For high volume production, the traditional deep drawing process is highly efficient since the production time of each part is considerably short and the high cost of the die and punch can be shared among a large number of parts. The conventional deep drawing was successfully implemented for several materials such as AA1050 alloy [1], AA1070 alloy [2], AA1080 alloy [3], AA1100 alloy [4], AA2014 alloy [5], AA2017 alloy [6], AA2024 alloy [7], AA2219 alloy [8], Ti-Al-4V alloy [9], EDD steel [10], gas cylinder steel [11]. However, for prototyping or small batch production, the manufacturing time, as well as the cost, of the die and punch is a large burden. Single point incremental forming does not require any dedicated dies or punches to form a complex shape and is therefore well adapted to rapid prototyping, as confirmed by several authors [16-18].

The present work was to predict formability of single point incremental deep drawing of AA1070 sheet for conical cups. The investigation was to optimize the process parameters such as blank thickness, step depth, coefficient of friction and tool radius. The design of experiments was carried out using Taguchi technique. The single point incremental deep drawing was implemented using the finite element analysis software code namely ABAQUS.

\section{MATERIALS AND METHODS}

In the present work, AA1070 sheet metal was used to make conical frustum cups. The levels chosen for the controllable process parameters are summarized in table 1 . Each of the process parameters was chosen at three levels. The orthogonal array, L9 was preferred to carry out experimental and finite element analysis (FEA). The obligation of parameters in the OA matrix is given in Table 2.

Table -1: Control parameters and levels

\begin{tabular}{|l|l|l|l|l|}
\hline Factor & Symbol & Level-1 & Level-2 & Level-3 \\
\hline Blank thickness, mm & A & 1.0 & 1.2 & 1.5 \\
\hline Step depth, mm & B & 0.50 & 0.75 & 1.00 \\
\hline Tool radius, mm & C & 4.0 & 5.0 & 6.0 \\
\hline Coefficient of friction & D & 0.05 & 0.10 & 0.15 \\
\hline
\end{tabular}

Table -2: Orthogonal array (L9) and control parameters

\begin{tabular}{|l|l|l|l|l|}
\hline Treat No. & A & B & C & D \\
\hline 1 & 1 & 1 & 1 & 1 \\
\hline 2 & 1 & 2 & 2 & 2 \\
\hline 3 & 1 & 3 & 3 & 3 \\
\hline 4 & 2 & 1 & 2 & 3 \\
\hline 5 & 2 & 2 & 3 & 1 \\
\hline 6 & 2 & 3 & 1 & 2 \\
\hline 7 & 3 & 1 & 3 & 2 \\
\hline 8 & 3 & 2 & 1 & 3 \\
\hline 9 & 3 & 3 & 2 & 1 \\
\hline
\end{tabular}

The finite element modeling and analysis was established using ABAQUS software. The rectangular sheet blank was created with desired diameter and thickness using CAD tools. The sheet was meshed with S4R shell elements [15] as shown in fig.1. The cylindrical single point tool was also modeled with appropriate inner and outer radius and corner radius using $\mathrm{CAD}$ tools (Fig. 1). The mechanical interface 
between the contact surfaces was implicated to be frictional contact and modeled as Coulomb's friction model [19]. In the present work, profile tool path technique was used as shown in fig.2. In profile tool path which was generated using CAD/CAM software [20], tool moves in one plane till it reaches to its initial point. Thereafter it moves vertically downward direction by specified step depth. After reaching to next plane tool continues its motion in the same direction as that of earlier cycle. This process continues till the complete geometry is formed.

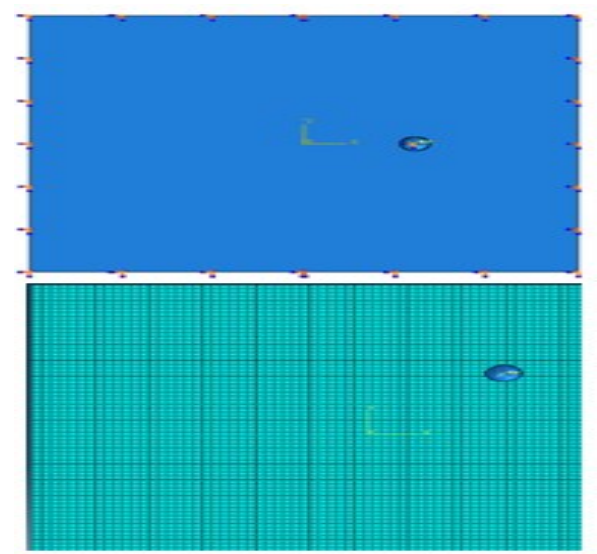

Fig -1: Modeling of sheet and single point tool.

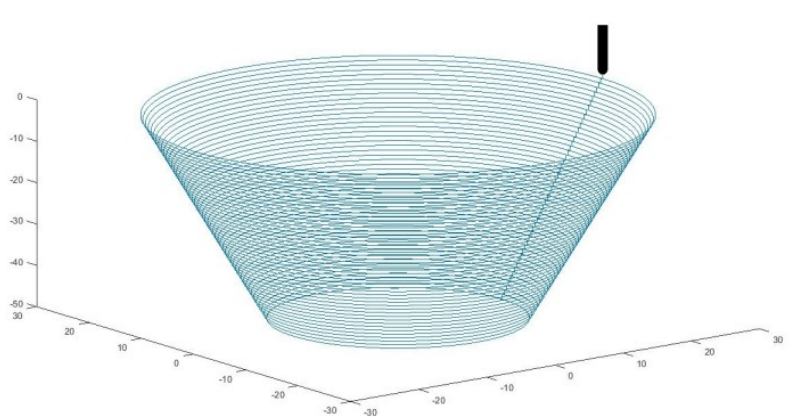

Fig -2: Profile tool path

\section{RESULTS AND DISCUSSION}

In the present work, the significance of process parameters should have at least $90 \%$ of confidence. Hence, the process parameters which had an absolute Fisher's ratio larger than 3.4579 were believed to influence the average value for the forming characteristic under null hypothesis, parameters which had Fisher's ratio less than 3.457 were believed to have no effect on the average.

\subsection{Effect of Process Parameters on Effective Stress}

In table -3 , the percent contribution indicates that the major influences are of tool radius, coefficient of friction and step depth. Fig-3(a) presents the effective stress induced in AA1070 alloy during incremental deep drawing process as a function of blank thickness. The effective stresses was increased linearly with the sheet thickness. The effective stress was increased with the increase of step depth initially from 0.50 to $0.75 \mathrm{~mm}$ and then it was decreased from 0.75 to $1.0 \mathrm{~mm}$ (Fig-3b). The effective stress was low for tool radius of $5 \mathrm{~mm}$ as shown in Fig-3(c). Fig-3(d) describes the effective stress as a function of coefficient of friction. The effective stress was decreased with the increase of coefficient of friction. The principal stresses $\mathrm{S}_{11}, \mathrm{~S}_{22}$ and shear stress $S_{12}$ are shown in Figs- 4, 5 and 6, respectively.

Table -3: ANOVA summary of the effective stress

\begin{tabular}{|c|c|c|c|c|c|c|c|c|}
\hline Source & Sum 1 & Sum 2 & Sum 3 & SS & v & V & F & P \\
\hline A & 604.9 & 606.3 & 610.8 & 6.32 & 1 & 6.33 & 844.00 & 7.16 \\
\hline B & 603.5 & 611.2 & 607.3 & 9.86 & 1 & 9.87 & 1316.00 & 11.17 \\
\hline C & 606.4 & 600 & 615.6 & 40.98 & 1 & 40.99 & 5465.33 & 46.43 \\
\hline D & 613.8 & 608 & 600.2 & 31.03 & 1 & 31.04 & 4138.66 & 35.16 \\
\hline e & & & & 0.03 & 4 & 0.008 & 1.00 & 0 \\
\hline T & 2428.6 & 2425.5 & 2433.9 & 88.23 & 8 & & & 100 \\
\hline
\end{tabular}

Note: SS is the sum of square, $\mathrm{v}$ is the degrees of freedom, $\mathrm{V}$ is the variance, $\mathrm{F}$ is the Fisher's ratio, $\mathrm{P}$ is the percentage of contribution and $\mathrm{T}$ is the sum squares due to total variation.
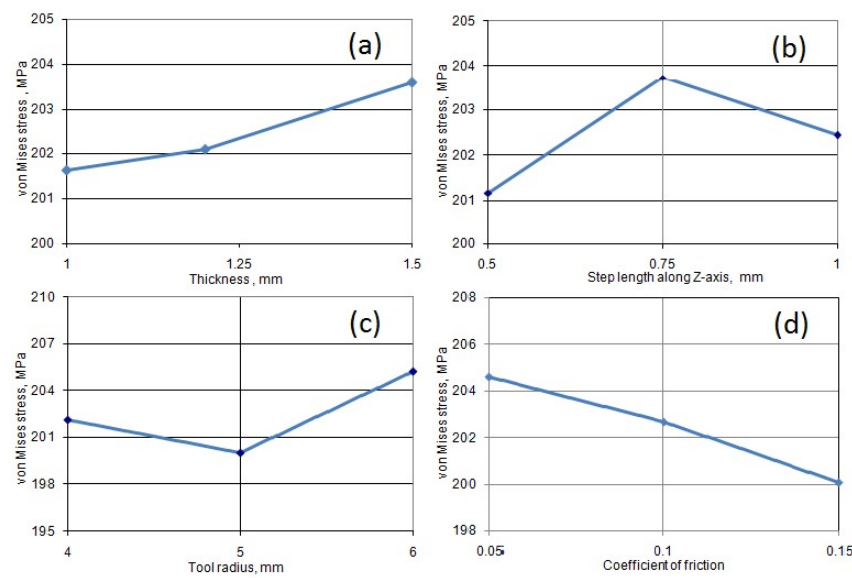

Fig -3: Effect of process parameters on von effective stress.

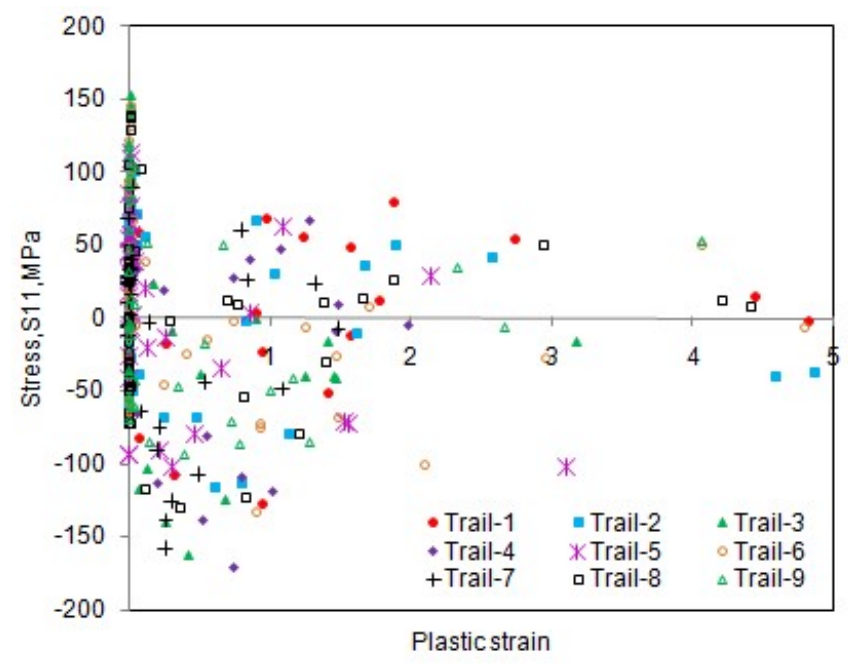

Fig -4: Effect of process parameters on $\mathrm{S}_{11}$. 


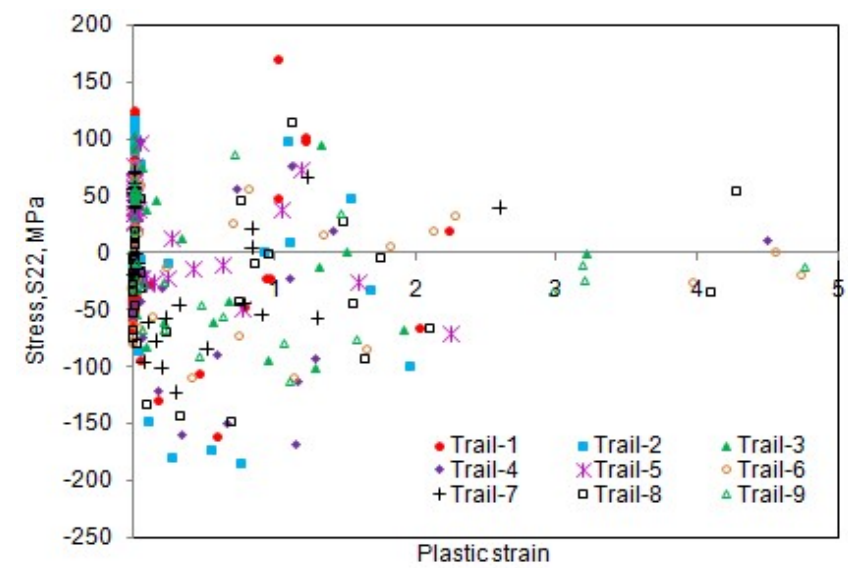

Fig- 5: Effect of process parameters on $\mathrm{S}_{22}$.

The compressive stresses induced in the blank sheet were higher in number than the tensile stresses. The plastic deformation was compressive for the strain less than 2.0. The shear stress developed in the blank sheet is nearly $40 \%$ to $50 \%$ of $\mathrm{S}_{11}$ or $\mathrm{S}_{22}$.

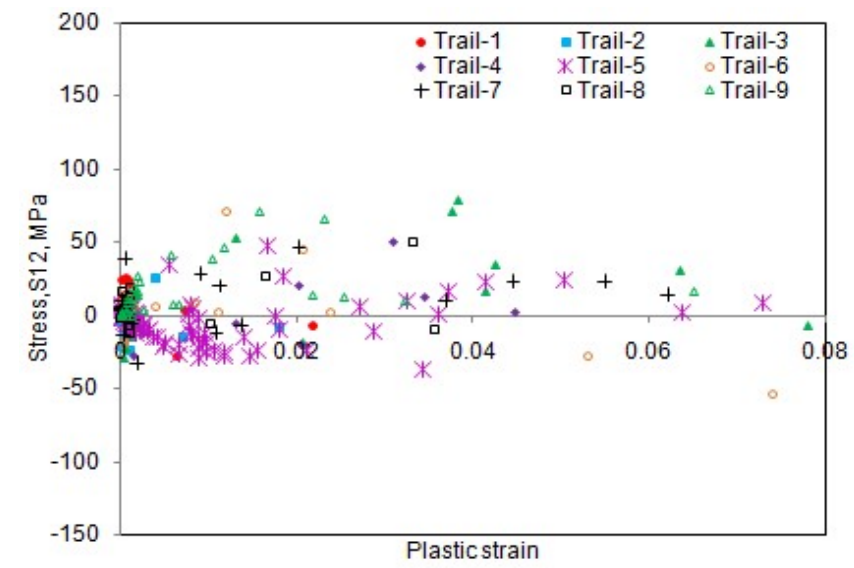

Fig- 6: Effect of process parameters on $\mathrm{S}_{12}$.

\subsection{Effect of Process Parameters On Strain Rate}

In table -4 , the percent contributions in the decreasing order of influence are $47.20 \%, 34.35 \%, 14.46 \%$ and $3.99 \%$, respectively, for tool radius, sheet thickness, step depth and coefficient of friction. The strain rate was low for the sheet thickness of $1.2 \mathrm{~mm}$ and step depth of $0.75 \mathrm{~mm}$ (Fig -7a and $7 b)$. The strain rate was increased with increase of tool radius (Fig -7c). The effect of coefficient of friction on strain rate was very minimal. The values of strain rate show severity of plastic deformation during the SPIF deep drawing of AA1070.

Table -4: ANOVA summary of the strain rate

\begin{tabular}{|c|c|c|c|c|c|c|c|c|}
\hline Source & Sum 1 & Sum 2 & Sum 3 & SS & v & V & F & P \\
\hline A & 58.56 & 35.98 & 44.22 & 87.04 & 1 & 87.04 & 91621.05 & 34.35 \\
\hline B & 54.45 & 40.02 & 44.29 & 36.64 & 1 & 36.64 & 38568.42 & 14.46 \\
\hline C & 30.97 & 51.84 & 55.95 & 119.61 & 1 & 119.61 & 125905.26 & 47.2 \\
\hline D & 43.35 & 50.68 & 44.73 & 10.11 & 1 & 10.11 & 10642.10 & 3.99 \\
\hline e & & & & -0.004 & 4 & -0.001 & 1.00 & 0 \\
\hline T & 187.33 & 178.52 & 189.19 & 253.4 & 8 & & & 100 \\
\hline
\end{tabular}
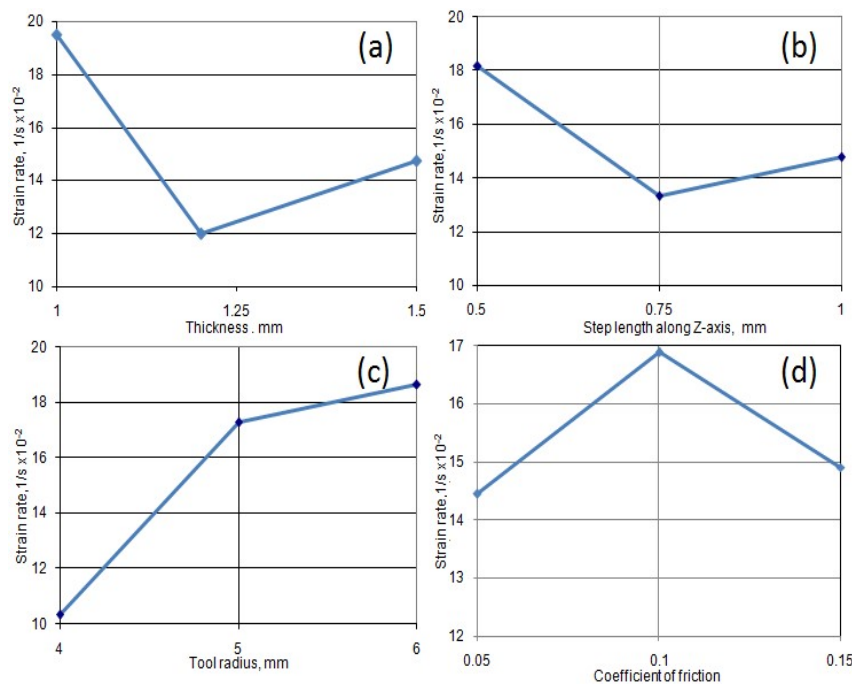

Fig -7: Effect of process parameters on strain rate.

\subsection{Effect of Process Parameters On Thickness}

\section{Reduction}

In table -5 , the percent contribution indicates that the parameter $\mathrm{C}$, tool radius, all by itself contributes the most towards the variation in the thickness reduction: almost $74.38 \%$. The sheet thickness (A) controls $14.09 \%$ of the total variation observed in thickness reduction. The step depth (B) and coefficient of friction (D) had negligible influence on the reduction of sheet thickness. As seen from Fig -8 , the reduction of thickness was increased with increase of sheet thickness (Fig -8a), with increase of step depth (Fig -8b) and with increase of tool radius (Fig -8c).

Table -5: ANOVA summary of the thickness reduction

\begin{tabular}{|c|c|c|c|c|c|c|c|c|}
\hline Source & Sum 1 & Sum 2 & Sum 3 & SS & v & V & F & P \\
\hline A & 254.03 & 257.58 & 257.8 & 2.97 & 1 & 2.98 & 752.31 & 14.09 \\
\hline B & 255.167 & 256.29 & 257.95 & 1.29 & 1 & 1.3 & 328.19 & 6.14 \\
\hline C & 250.95 & 258.39 & 260.06 & 15.70 & 1 & 15.71 & 3966.05 & 74.38 \\
\hline D & 256.46 & 255.18 & 257.77 & 1.11 & 1 & 1.11 & 280.22 & 5.24 \\
\hline e & & & & 0.016 & 4 & 0.004 & 1.00 & 0 \\
\hline T & 1016.61 & 1027.45 & 1033.58 & 21.1 & 8 & & & 100 \\
\hline
\end{tabular}
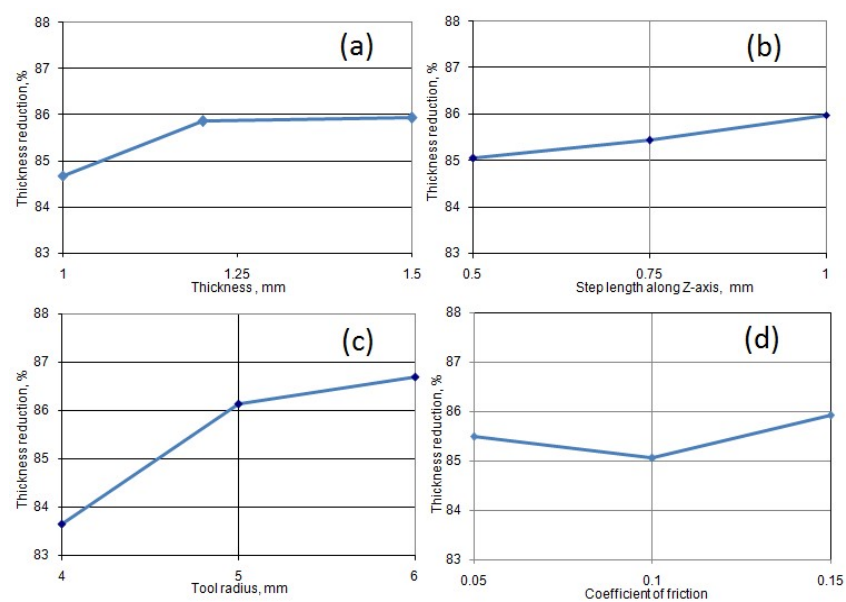

Fig -8: Effect of process parameters on thickness reduction. 


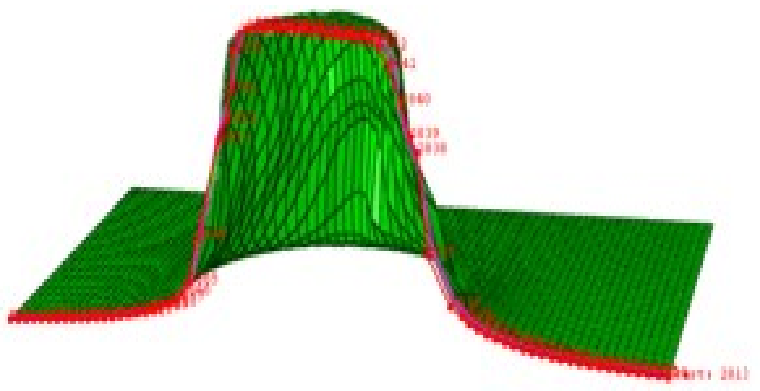

Fig- 9: Location of thickness reduction in the deformed cup.

The variation of thickness was considered at the center-line of the deformed cup as shown in Fig -9. As observed from Fig -10 , the majority of thickness reduction takes place in the walls of the cup but not in the flange or bottom of the cup. The elements located at the mid regions of the walls are elongated higher than those present at the top and bottom of the cup walls.
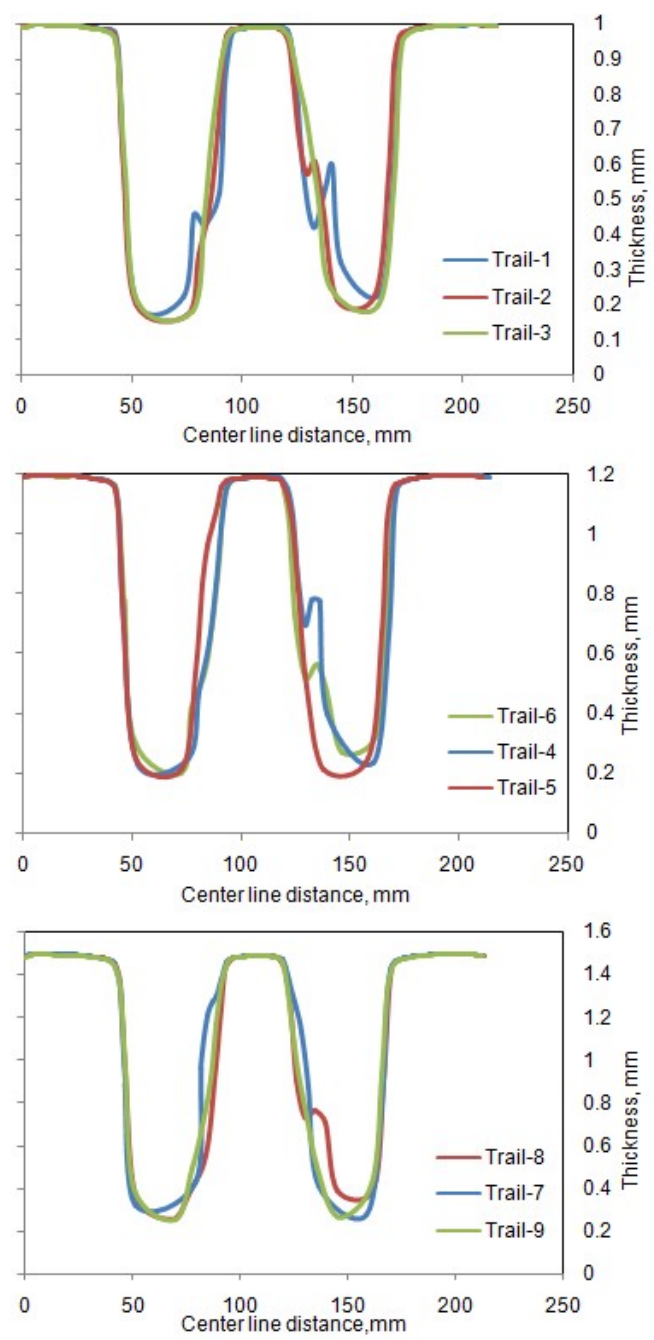

Fig- 10: Effect of process parameters on thickness reduction.

\subsection{Formability of SPI Deep Drawing Process}

The formability diagrams of the cups are shown in Figs -11 , 12 and 13. Tension is highly dominated during the formation of blank sheet. For the trials 1, 2 and 3, the von
Mises stresses are respectively, $202 \mathrm{MPa}, 201 \mathrm{MPa}$ and 202 MPa. For the trials 4, 5 and 6, the von Mises stresses are, respectively, $196 \mathrm{MPa}, 208 \mathrm{MPa}$ and $202 \mathrm{MPa}$. For the trials 7,8 and 9 , the von Mises stresses are, respectively, $205 \mathrm{MPa}, 202 \mathrm{MPa}$ and $203 \mathrm{MPa}$. The safe tensile and compressive strain should be less than 0.4 to prevent the rupture in the cups. The formability of 7 th trial was excellent as compared to the rest of the trials.

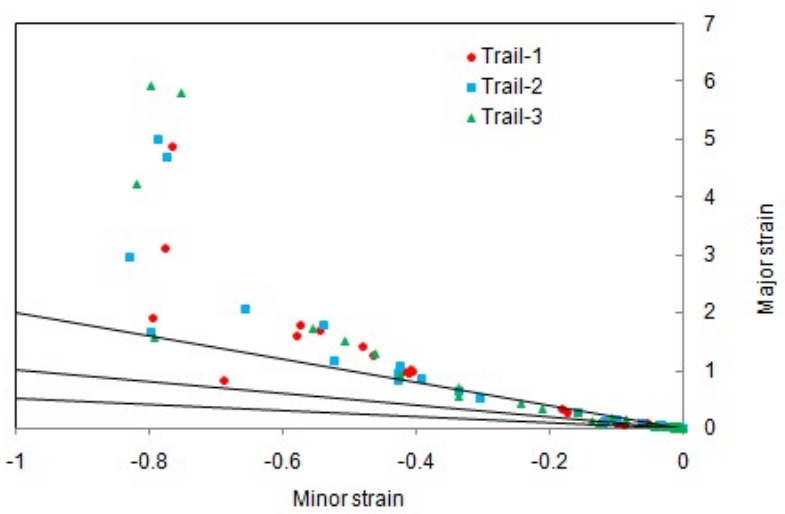

Fig -11: Forming limit diagram for trials 1, 2, 3.

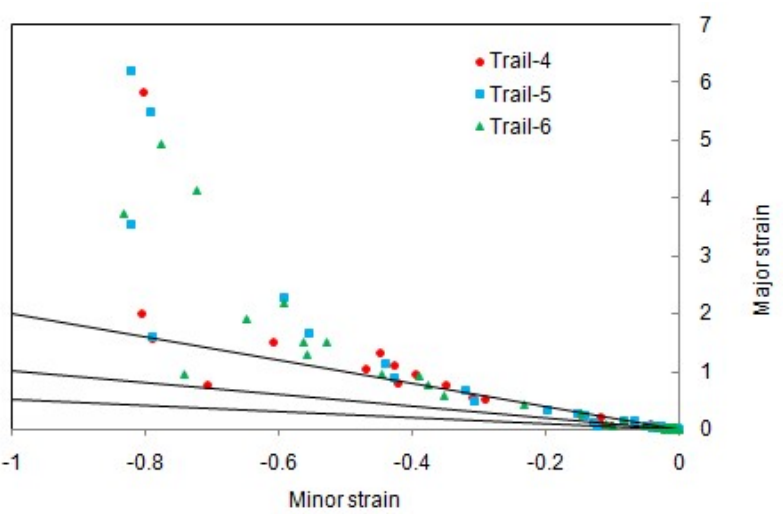

Fig -12: Forming limit diagram for trials 4, 5, 6.

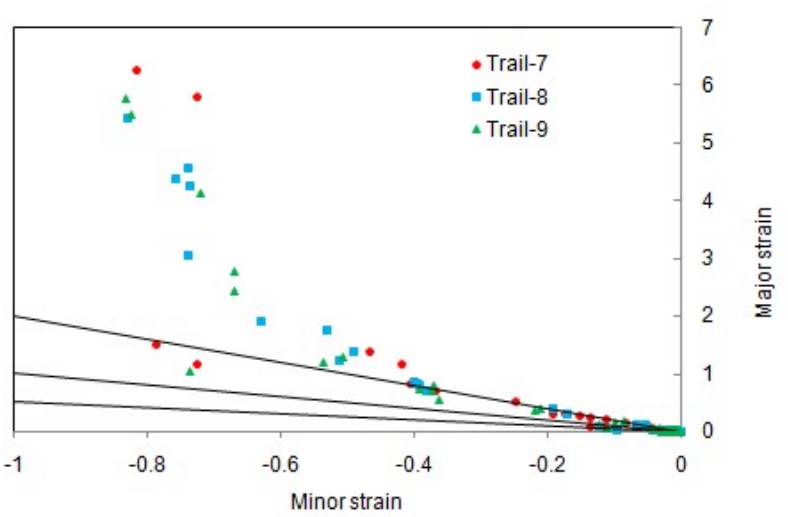

Fig-13: Forming limit diagram for trials 7, 8, 9.

It is observed from Fig -14 that the high stresses are induced at the bottom corners, along the edges and walls of the cups. In all the cases the von Mises stress was higher than the ultimate tensile strength of the sheet material. When the stress induced in the sheet was higher than the tensile strength there is likelihood of fracture of cups due to uniaxial tension in deep drawing process [21-23]. 

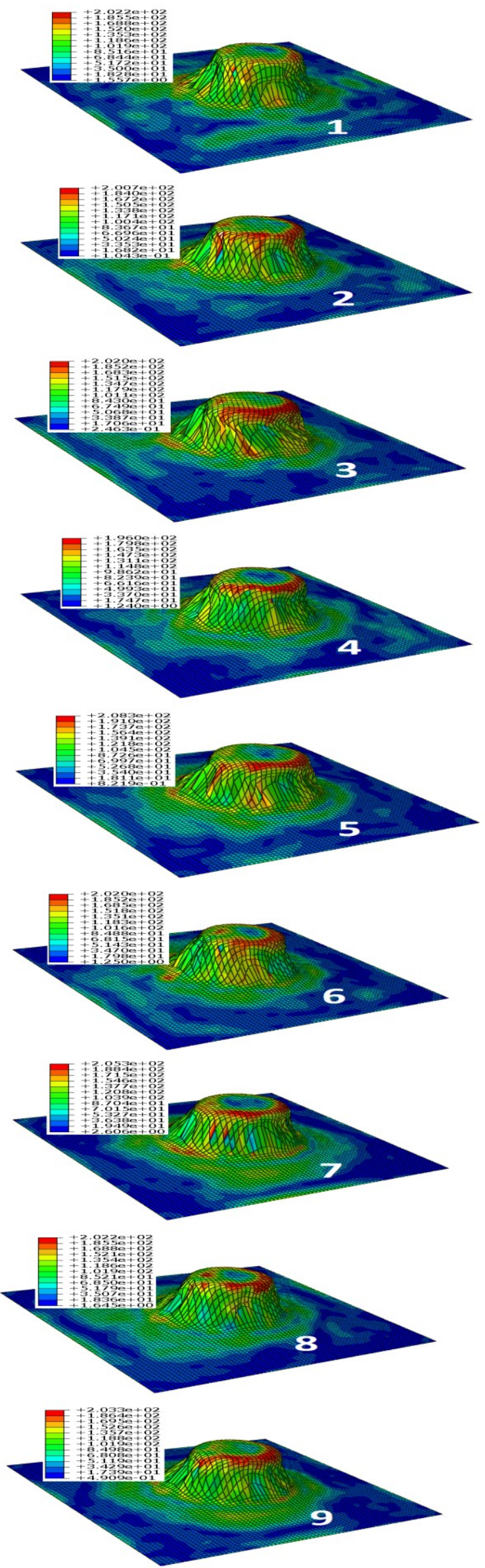

\section{CONCLUSION}

In the present work, the finite element analysis and Taguchi techniques are successfully implemented to simulate single point incremental deep drawing process for conical cups from AA1070 alloy sheet. The major parameters, which influence the formability of conical cups, are the tool radius and coefficient of friction.

\section{ACKNOWLEDGEMENT}

The authors wish to thank University Grants Commission (UGC), New Delhi for the support of this work.

\section{REFERENCES}

[1] A. C. Reddy, Homogenization and Parametric Consequence of Warm Deep Drawing Process for 1050A Aluminum Alloy: Validation through FEA. International Journal of Science and Research, 4 (4), 2015, pp. 2034-2042.

[2] K. Chandini,. A. C. Reddy, Finite Element Analysis of Warm Deep Drawing Process for Pyramidal Cup of AA1070 Aluminum Alloy. International Journal of Advanced Research, 3(6), 2015, pp. 1325-1334.

[3] B. Yamuna, A. C. Reddy, Finite Element Analysis of Warm Deep Drawing Process for Conical Cup of AA1080 Aluminum Alloy. International Journal of Advanced Research, 3(6), 2015, pp. 1309-1317.

[4] T. Srinivas, A. C. Reddy, Finite Element Analysis of Warm Deep Drawing Process for Rectangular Cup of AA1100 Aluminum Alloy. International Journal of Advanced Research, 3(6), 2015, pp. 1383-1391.

[5] A. C. Reddy, Parametric Optimization of Warm Deep Drawing Process of 2014T6 Aluminum Alloy Using FEA. International Journal of Scientific \& Engineering Research, 6(5), 2015, pp.1016-1024.

[6] A. C. Reddy, Finite Element Analysis of Warm Deep Drawing Process for 2017T4 Aluminum Alloy: Parametric Significance Using Taguchi Technique. International Journal of Advanced Research, 3(5), 2015, pp. 1247-1255.

[7] A. C. Reddy, Parametric Significance of Warm Drawing Process for 2024T4 Aluminum Alloy through FEA," International Journal of Science and Research, 4(5), 2015, pp. 2345-2351.

[8] A. C. Reddy, Formability of High Temperature and High Strain Rate Superplastic Deep Drawing Process for AA2219 Cylindrical Cups. International Journal of Advanced Research, 3(10), 2015, pp. 1016-1024.

[9] A. C. Reddy, High temperature and high strain rate superplastic deep drawing process for AA2618 alloy cylindrical cups," International Journal of Scientific Engineering and Applied Science, 2(2), 2016, pp. 3541.

[10] A. C. Reddy, Practicability of High Temperature and High Strain Rate Superplastic Deep Drawing Process for AA3003 Alloy Cylindrical Cups. International Journal of Engineering Inventions, 5(3), 2016, pp. 1623.

Fig -14: Raster images of von Mises stress in the cups 
[11] A. C. Reddy, Suitability of High Temperature and High Strain Rate Superplastic Deep Drawing Process for AA5052 Alloy. International Journal of Engineering and Advanced Research Technology, 2(3), 2016, pp. 11-14.

[12] A. C. Reddy, High temperature and high strain rate superplastic deep drawing process for AA5049 alloy cylindrical cups. International Journal of Engineering Sciences \& Research Technology, 5(2), 2016, pp. 261268.

[13] A. C. Reddy, Finite element analysis of reverse superplastic blow forming of Ti-Al-4V alloy for optimized control of thickness variation using ABAQUS. Journal of Manufacturing Engineering, 1(1), 2006, pp.6-9.

[14] A. C. Reddy, T. K. K. Reddy, M. Vidya Sagar, Experimental characterization of warm deep drawing process for EDD steel. International Journal of Multidisciplinary Research \& Advances in Engineering, 4(3), 2012, pp.53-62.

[15] A. C. Reddy, Evaluation of local thinning during cup drawing of gas cylinder steel using isotropic criteria. International Journal of Engineering and Materials Sciences, 5(2), 2012, pp.71-76.

[16] G. Hirt, S. Junk, and N. Witulski. Incremental Sheet Forming: Quality Evaluation and Process Simulation, In Proceedings of the 7th ICTP conference, 1, 2002, pp. 925-930.

[17] D. Leach, A. J. Green, and A. N. Bramley. A New Incremental Sheet Forming Process for Small Batch and Prototypes Parts, In Proceedings of the 9th International Conference on Sheet Metal, 2001, pp. 211-218.

[18] S. J. Yoon and D. Y. Yang. Development of a Highly Flexible Incremental Roll Forming Process for the Manufacture of a Doubly Curved Sheet Metal. CIRP Annals - Manufacturing Technology, 52, 2003, pp. 201-204.

[19] C. R Alavala, Finite element methods: Basic Concepts and Applications, PHI Learning Pvt. Ltd., 2008.

[20] C. R. Alavala, CAD/CAM: Concepts and Applications, PHI Learning Pvt. Ltd, 2008.

[21] A. C. Reddy, Formability of Warm Deep Drawing Process for AA1050-H18 Pyramidal Cups. International Journal of Science and Research, 4(7), 2015, pp. 2111-2119.

[22] A. C. Reddy, Formability of Warm Deep Drawing Process for AA1050-H18 Rectangular Cups. International Journal of Mechanical and Production Engineering Research and Development, 5(4), 2015, pp. 85-97.

[23] A. C. Reddy, Formability of superplastic deep drawing process with moving blank holder for AA1050-H18 conical cups. International Journal of Research in Engineering and Technology, 4(8), 2015, pp. 124-132. 